(C) Entomologica Fennica. 15 January 2009

\title{
Two new species of the genus Bothropolys Wood, 1862 (Chilopoda: Lithobiomorpha: Lithobiidae) from China
}

\author{
Hui-Qin Ma, Da-Xiang Song* \& Ming-Sheng Zhu
}

Ma, H.-Q., Song, D.-X. \& Zhu, M.-S. 2008: Two new species of the genus Bothropolys Wood, 1862 (Chilopoda: Lithobiomorpha: Lithobiidae) from China. — Entomol. Fennica 19: 248-256.

The present paper deals with two new species of the genus Bothropolys Wood, 1862 (Lithobiomorpha: Lithobiidae), recently discovered in China. Bothropolys stoevi sp. n. was found in Hebei and Shanxi Provinces, and Bothropolys edgecombei sp. n. was found in Sichuan Province. We present a key and distributional map of the Chinese Bothropolys species.

H.-Q. Ma, Scientific Research Office, Hengshui University, Hengshui, Hebei 053000, P. R. China, and College of Life Sciences, Hebei University, Baoding, Hebei 071002, P. R. China

D-X. Song, College of Life Sciences, Hebei University, Baoding, Hebei 071002, P. R. China, and Jiangsu Key Laboratory for Biodiversityand Biotechnology, College of Life Sciences, Nanjing Normal University, Nanjing, Jiangsu 210097, P. R. China; *Corrsponding authorsE-mail: dxsong2002@yahoo.com.cn M.-S. Zhu, College of Life Sciences, Hebei University, Baoding, Hebei 071002, P. R. China

Received 1 September 2007, accepted 26 November 2007

\section{Introduction}

The genus Bothropolys Wood, 1862 was originally proposed as a genus in the family Lithobiidae, characterized by the existence of numerous irregularly arranged pores on coxae of the last four pairs of legs and by the antenna composed of 20 antennomeres. Presently, the genus comprises 31 species (Attems 1938, 1953, Verhoeff 1938a, b, Takakuwa 1939, 1940, Takakuwa \& Takashima 1949, Chamberlin \& Wang 1952, Matic 1974, Wang \& Mauriès 1996, summary by Zapparoli 2006). Bothropolys species are hitherto known from eastern and southern China, Indo-China, Korea, Japan, the Philippines, New Guinea, and the Hawaiian Is. (Takakuwa 1940, Zapparoli \& Shelley 2000), North America (Chamberlin 1925), and central Asia around Tashkent, Uz- bekistan and Kirghizstan (Zalesskaja 1978, Eason 1997). The myriapod fauna of China, is still poorly known, in particular, as regards the Lithobiomorpha, and only 5 species of Bothropolys have been described (Wang \& Mauriès 1996, Chao 2005). On examining our collection from Hebei, Shanxi and Sichuan Provinces, we came across two new species of Bothropolys. The descriptions of these two new species are given below.

\section{Materials and methods}

All the materials were collected by hand or with forceps under stones while Barber pitfall traps were used only occasionally. All centipedes examined were preserved in $75 \%$ ethanol. Speci- 
mens were examined with the aid of a Motic-C stereoscope, made in China. All materials, including type specimens are deposited in the College of Life Sciences, Hebei University, Baoding, China.

The following abbreviations are used in the text and tables: T: tergite, N: number, C: coxa, Tr: trochanter, P: prefemur, F: femur, t: tibia, a: anterior, m: median, p: posterior, To: Tömösváry's organ.

\section{Taxonomy}

Chilopoda Latreille, 1817

Lithobiomorpha Pocock, 1895

Lithobiidae Newport 1844

Ethopolyinae Chamberlin 1925

Bothropolys Wood, 1862

\subsection{Bothropolys stoevi sp. n. (Fig. 1)}

Type material. Holotype: $\widehat{\partial}$ (Fig. 1 a), body length $17.6 \mathrm{~mm}$, from Fanzhi County, Shanxi Province, $39^{\circ} 12^{\prime} 26.5^{\prime \prime} \mathrm{N} 113^{\circ} 15^{\prime} 29.3^{\prime}$ 'E, altitude 980 m a.s.1., 5.X.2005, leg. Hui-Qin Ma.

Paratypes: $2+9$, same locality as holotype.

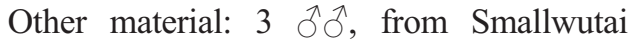
Mountain, Yu County, Hebei Province, $39^{\circ} 83^{\prime} \mathrm{N}$ $114^{\circ} 53^{\prime} \mathrm{E}$, altitude 1,300 $\mathrm{m}$ a.s.1., 20.VIII.2005, leg. Zhi-Sheng Zhang, Zi-Zhong Yang and HuiQin Ma; 1 ô, 1 \%, Smallwutai Mountain, Yu County, Hebei Province, 20.IX.2005, leg. Feng Zhang and Zi-Zhong Yang.

Diagnosis. Maximum length of body (from anterior margin of the head shield to posterior end of telson) up to $20.5 \mathrm{~mm}$, antennae composed of 20-21 antennomeres, commonly 20; 20-22 ocelli on each side; Tömösváry's organ moderately large, rounded, almost equal to adjoining ocelli; $6+6,6+7$ or $7+7$ blunt prosternal teeth, usually $6+6$, terminal part of each tooth truncated; porodonts feebly thicker, posterolateral to lateral tooth; posterior angles of T7 gently triangular, posterior angles of T9, T11 and T13 sharply triangular; female gonopods with two moderately long, coniform spurs and tridentate claws.

Description. Body length: 15.1-20.5 mm.

Colour (based on specimens in $75 \%$ ethanol) of antennae red-brown, colour of basal antennomeres deeper, distal article orange; head shield orange to chocolate; tergites pale orange to fuscous with pale white mottling concentrated in longitudinal median band; last two tergites chocolate; maxillipeds and last two sternites chocolate; sternites pale yellow to pale gray, sternites 14 and 15 pale fuscous, genital sternite and gonopods brown.

Head shield smooth, anterior margin ridge is moderately thickened medially (Fig. 1 b), with shallow median notch, posterior margin transverse.

Antennae as long as 3.5 (individual variation 3.3-3.7) times the width of head shield, usually extending back to T4; 20 (individual variation 20-21) antennomeres, commonly 20 antennomeres; basal antennomere length about equal to width, and succeeding antennomeres typically longer than their width; distal antennomere up to three times as long as wide.

Abundant setae inserted on antennal surface, but fewer setae on both ventral and dorsal side in basal antennomeres, gradual increase in density of setae to about seventh (individual variation eighth) antennomere, then more or less constant.

22 (individual variation 20-22) ocelli (Fig. 1 c) on each side, in 4 irregular rows, the terminal one comparatively larger, other ocelli about equal in size, overhanging lateral margin of head; ocelli moderately domed, translucent, usually darkly pigmented basally, field of ocelli slightly dark.

Tömösváry's organ (Fig. 1 c-To) moderately large, rounded, about equal to adjoining ocelli, lying on ventral margin of head immediately proventral to ocelli.

Maxilliped coxosternite trapezoidal (Fig. 1 d), dental margin moderately broad, each half nearly straight, not convex; outboard comparatively longer than inboard, sloping to inboard; median notch at most narrow, moderately deep, parabolic or semicircular. Dental margin with $6+6$ (individual variation $6+7$ or $7+7$ ) teeth; teeth moderately large and blunt, terminal part of each tooth truncated (Fig. 1 e), usually outer teeth more distant than inner teeth; porodonts feebly thicker, posterolateral to lateral tooth; coxosternum bearing moderate number of long, scattered setae, usually with distinctly denser setae near dental margin. 


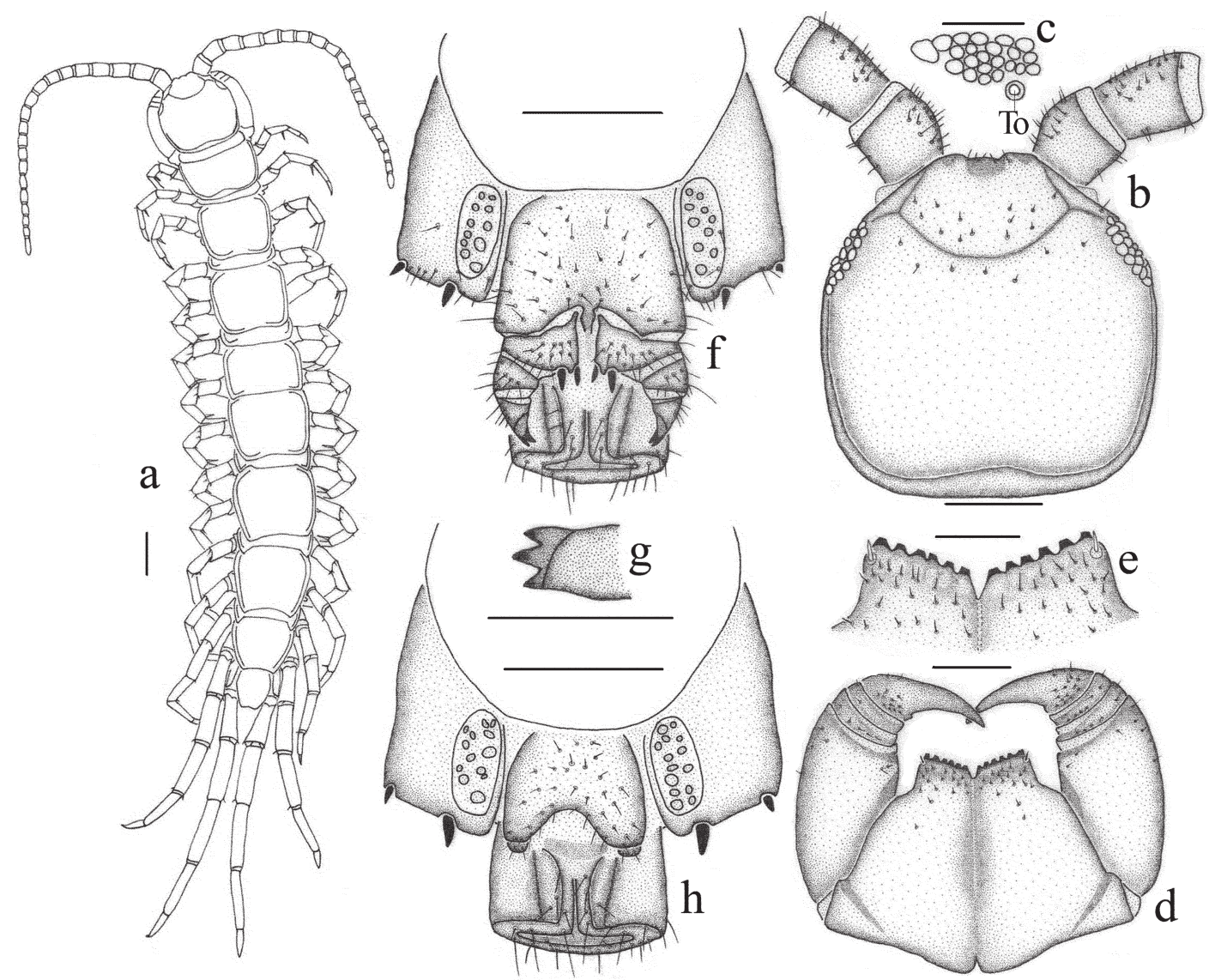

Fig. 1. Bothropolys stoevi n. sp. - a. Holotype, male, scale $1 \mathrm{~mm}$. - b. Holotype, head, dorsal view, scale 500 $\mu \mathrm{m}$. - c. Holotype, right ocelli and Tömösváry's organ (c-To), scale $250 \mu \mathrm{m}$. - d. Holotype, maxilliped coxosternum, ventral view, scale $500 \mu \mathrm{m}$. - e. Holotype, dental margin of maxilliped coxosternum, scales $250 \mu \mathrm{m}$. -f. Paratype, female, posterior segments and gonopods, scale $500 \mu \mathrm{m}$. - g. Paratype, female, claw of gonopods, scale $250 \mu \mathrm{m}$. $-\mathrm{h}$. Holotype, male, posterior segments and gonopods, scale $500 \mu \mathrm{m}$.

Tergites often weakly wrinkled, gently turned up against borders. T1 trapeziform, slightly wider than T3 and head shield, T10 widest. Lateral border subparallel in T3 and T5, slightly convex in T2, T4, T6, T8, T10, T12 and T14; lateral border strongly convex in T15; medial sector of posterior margin of $\mathrm{T} 7$ straight or feebly convex, posterior angles gently triangular; posterior angles of T9, T11 and T13 sharply triangular (Fig. 1 a). Posterior margin of T1, T3, T5, T8 and T10 gently concave, posterior angles rounded; posterior margin of T12, T14 and T15 deeply concave, posterior angles of T12 obtusely triangular, T14 and T15 sharply triangular.

Short to moderately long, slender setae along the lateral borders of all tergites, often with 5-8 longer, thicker setae concentrated on anterolateral border; 3-5 short setae concentrated on posterior angles of tergites; few short, slender setae scattered sparsely over surface of all tergites.

A few short, slender setae scattered sparsely over the surface of all sternites, a few short to moderately long setae on margins of sternites, 13 longer setae at anterolateral angles and posterolateral angles; setae along posterior margins more prominent in posterior segments; many more setae on posterior of sternites 13-15; posterior margin fringed with some setae on sternites 14 15 ; consistently strong pair of setae on anteromedial part of sternites.

Legs strong; prefemur, femur, tibia of legs 1- 
Table 1. Leg spinulation of Bothropolys stoevi sp. $\mathrm{n}$. Letters in brackets indicate individual variation in spinulation. Abbreviations: C, coxa, Tr, trochanter, P, prefemur, F, femur, t, tibia; a, anterior, m, median, p, posterior.

\begin{tabular}{|c|c|c|c|c|c|c|c|c|c|c|}
\hline \multirow[b]{2}{*}{ Legs } & \multicolumn{5}{|c|}{ Ventral } & \multicolumn{5}{|c|}{ Dorsal } \\
\hline & C & $\operatorname{Tr}$ & $P$ & $\mathrm{~F}$ & $\mathrm{t}$ & $C$ & $\mathrm{Tr}$ & $P$ & $\mathrm{~F}$ & $\mathrm{t}$ \\
\hline 1 & & & $\mathrm{mp}$ & amp & $\mathrm{am}$ & & & amp & ap & $a$ \\
\hline 2 & $a(p)$ & & $\mathrm{mp}$ & amp & $a m$ & & & amp & ap & \\
\hline $3-6$ & & & $\mathrm{mp}$ & amp & $a m$ & & & amp & ap & ap \\
\hline $7-8$ & & & $\mathrm{mp}$ & amp & $\mathrm{am}$ & (m) & & amp & ap & ap \\
\hline $9-11$ & & & amp & amp & $\mathrm{am}$ & $\mathrm{m}$ & & amp & ap & $a p$ \\
\hline $12-13$ & & $\mathrm{~m}$ & amp & amp & $\mathrm{am}$ & $\mathrm{m}$ & & $\mathrm{amp}$ & $\mathrm{p}$ & $p$ \\
\hline 14 & am & $\mathrm{m}$ & amp & $\mathrm{am}$ & $a$ & $\mathrm{~m}$ & & amp & $p$ & $p$ \\
\hline 15 & $\mathrm{am}$ & $\mathrm{m}$ & amp & $\mathrm{m}$ & $a$ & $\mathrm{~m}$ & & amp & $p$ & \\
\hline
\end{tabular}

13 with short to moderately long setae scattered sparsely on the surface, setae shorter on dorsal than ventral side, thickened setae on the tibia. Basitarsus with slightly thicker setae aligned as one row on the middle of ventral sides, distitarsus with slightly thicker setae aligned as two rows on the middle of ventral sides, setae scattered sparsely on the other parts. Moderately thicker setae encircling distal margin of prefemur, femur and tibia of legs $1-15$, setae slightly sparser on sections of leg 13 than on anterior legs, setae prominently sparse on segments of legs 14 and 15 , but setae on tibia with only slightly change. Pretarsus claws on all legs, relatively long, curved ventrad; anterior and posterior accessory claws nearly symmetrical in legs 1-13, no accessory claws on legs 14 and 15. Distitarsus 35\% (individual variation $31 \%-37 \%$ ) length of tarsus on leg 15; basitarsus 6.5 (individual variation 6-8) times as long as wide. Leg spinulation in Table 1.

Coxal pores round or slightly ovate, 13-18 (individual variation 7-23) coxal pores irregularly arranged, females 10-23, males 7-20, females usually more than males. Coxal pore field set in a shallow groove, separated from anteroventral face of coxa by a rounded surface.

Female $15^{\text {th }}$ sternite straight or gently convex posteromedially. A few long, slender setae scattered sparsely over the surface of $15^{\text {th }}$ sternite. Tergites of genital segment and telson usually well sclerotised. Sternite of genital segment large, posterior margin concave between condyles of gonopods except for a small median approximately rhomboid bulge, terminally lightly sclero- tised, setae evenly scattered on sternite of genital segment; fringed with longer setae along posterior margin. Gonopods divided into three articles, first article bearing $2+2$ (rarely $3+3$ ) moderately large (Fig. $1 \mathrm{f}$ ), coniform spurs, inner spur slightly smaller than the outer. First and second articles with many short to moderately long setae; setae of first article usually arranged in 3 irregular rows, long setae concentrated in a row along posterior margin; setae of second article usually fairly scattered, usually four setae on the outer lateral part of third article. Claw broad, tridentate (Fig. $1 \mathrm{~g}$ ), outer and inner denticles smaller than the middle one.

Male $15^{\text {th }}$ sternite straight or gently convex posteromedially, fringed with few short setae along posterior margin, posterior angles rounded, nearly trapezoid. Few long, slender setae scattered sparsely over the surface of $15^{\text {th }}$ sternite. Tergites of genital segment usually well sclerotised. Sternite of genital segment large, posterior margin concave between condyles of gonopods, setae fairly evenly scattered on sternite of genital segment; fringed with longer setae along posterior margin. Gonopods are only a small hemispherical protuberance, with 2 (individual variation 2-4) long setae, distal slightly sclerotised (Fig. 1 h).

Habitat. The specimens have been collected from mixed coniferous broad leaved forest. They inhabit moderately moist soil or under roadside stones.

Etymology. The specific name is a patronym in honor of Dr. Pavel Stoev, a myriapodologist of 
Bulgaria, who made contributions to this research.

Discussion. The new species resembles $B$. shansiensis Takakuwa \& Takashima, 1949 from Shanxi Province, China (Takakuwa \& Takashima 1949), in the same number of teeth on the dental margin of maxilliped coxosternite, and the first article of the female gonopod bearing $2+2$ spurs. It can be easily distinguished from the latter by the teeth on the dental margin of the maxilliped coxosternite being truncated terminally instead of sharp, porodonts situated posterolateral to the lateral tooth rather than between outer two teeth, posterior angles of T9, T11 and T13 sharply projected in $B$. stoevi, vs. the posterior angles of each of T4, T6, T7, T9, T11 and T13 sharply projected in B. shansiensis.

\subsection{Bothropolys edgecombei sp. n. (Fig. 2)}

Type material. Holotype: + (Fig. 2 a), body length $23.1 \mathrm{~mm}$, from Qicenglougou Wolong County, Sichuan Province, 31 $04^{\prime} 32.7^{\prime} \mathrm{N}$ $103^{\circ} 18^{\prime} 55.1^{\prime \prime} \mathrm{E}$, altitude $1,419 \mathrm{~m}$ a.s.1., 19.VII. 2003, Zhi-shun Song leg.

Paratypes: 2 우 $0,3 \hat{\jmath} \hat{\jmath}$, same locality as holotype.

Diagnosis. Maximum length of body (from anterior margin of the head shield to posterior end of telson) up to $23.1 \mathrm{~mm}$, antennae composed of 20 antennomeres, 19-28 ocelli on each side; Tömösváry's organ moderately large, elliptical to rounded, moderately small or equal to adjoining ocelli; $7+7$ blunt prosternal teeth, seldom $7+8$, terminal part of each tooth transected; spine-like porodonts between the two outer teeth, posterior angles of T6, T7, T9, T11 and T13 sharply triangular; female gonopods with two moderately long, bullet-shaped spurs and tridentate claw.

Description. Body length: 13.6-23.1 mm.

Colour (based on specimens in $75 \%$ ethanol) of antennae light gray to beige, distal 5-6 antennomeres showing transition to yellowbrown, terminal antennomere yellow-brown; head shield yellow-brown to pale chocolate, tergites pale yellow-brown to yellow-brown with pale white mottling concentrated in longitudinal median band; distal two tergites dark yellowbrown; lateral margin of tergites with short setae; sternites and lateral of body light gray to pale chocolate; maxillipeds and coxosternum yellowbrown; last two sternites yellow-brown to beige; all legs light gray, distitarsus of maxillipeds black; sternites 14 and 15 pale red-brown; genital sternite yellow-brown.

Head shield smooth, slightly longer than wide in male, slightly wider than long in female; anterior margin ridge is moderately thickened medially, thinner than in B. stoevi, with shallow median notch; transverse suture clear, posterior margin of head shield straight, posterior border moderately thickened mediately (Fig. 2 b).

Antennae composed of $20+20$ (individual variation 20+21) antennomeres; antennae as long as 3.7 times the width of head shield, usually extending back to posterior part of $\mathrm{T} 4$; basal antennomere as long as wide, succeeding antennomeres typically longer than wide; terminal antennomere 3.6 (individual variation 3.0-4.0) times as long as wide; abundant setae on antennal surface, but fewer setae on both ventral and dorsal sides in basal articles, gradually increasing in density of setae to about sixth (individual variation seventh) antennomere, then more or less constant.

Ocelli 28 (individual variation 19-28) (Fig. 2 c) on each side, arranged in 4 irregular rows, terminal two ocelli comparatively larger, the others about equal in size, overhanging the anterior lateral margin of the head; ocelli gently bulging, domed, translucent, usually darkly pigmented at base, field of ocelli slightly dark.

Tömösváry's organ (Fig. 2 c-To) moderately large, rounded, slightly smaller or equal to adjoining ocelli, lying on the ventral margin of the head immediately proventral to the ocelli.

Maxilliped coxosternite approximately trapezoidal (Fig. 2 d), dental margin moderately broad, outboard of each half of dental margin lightly longer than inboard; median notch moderately deep, U-shaped; dental margin with 7+7 teeth (individual variation $7+8$ ), these moderately large and comparatively blunt, terminal part of each tooth truncated; spine-like porodonts between the two outer teeth (Fig. 2 e); usually outer teeth more distant than inner teeth; some scattered setae on ventral side of coxosternum, usually with moderately longer setae near the dental margin.

Except for head shield and T1, all tergites 

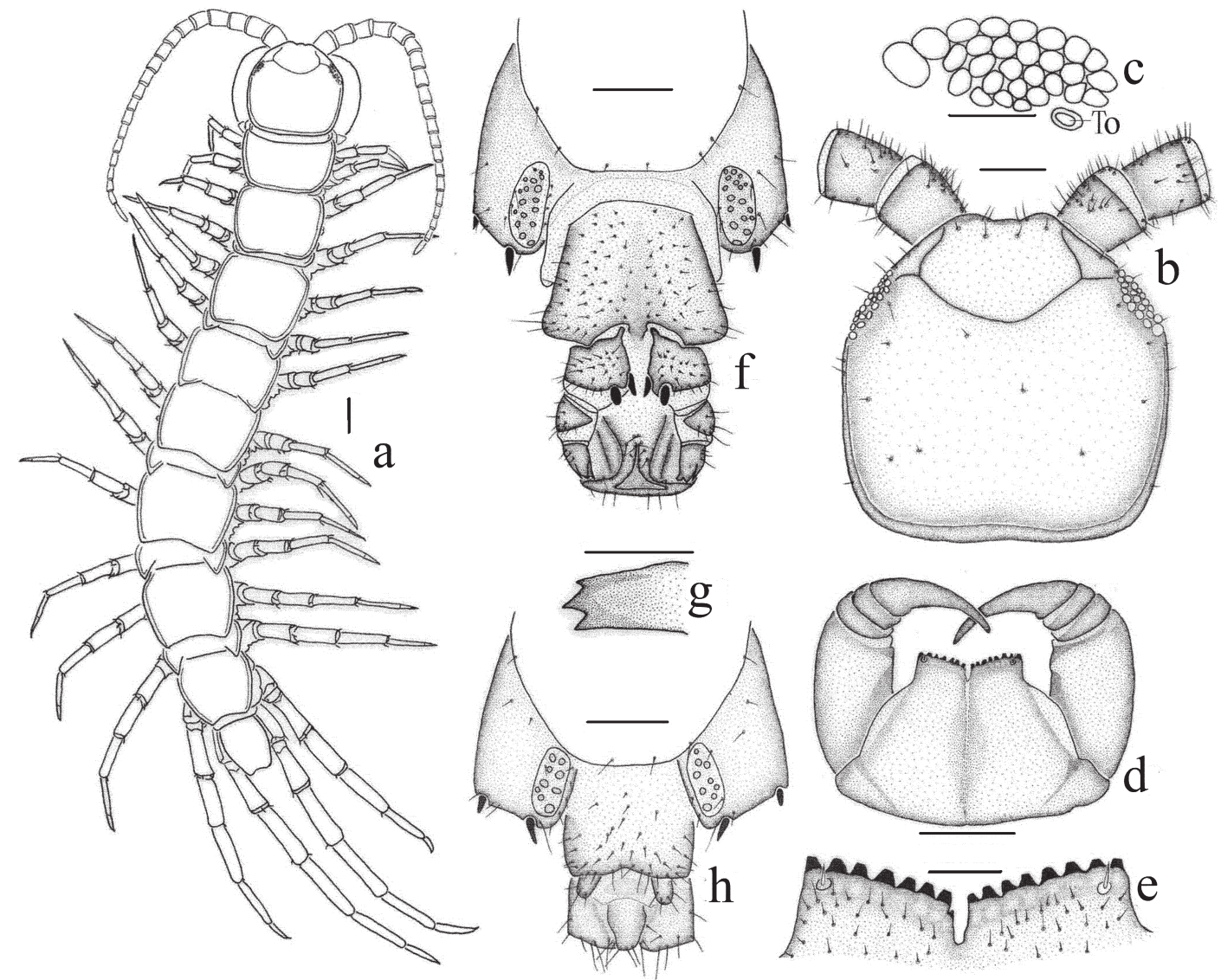

Fig. 2. Bothropolys edgecombei n. sp. - a. Holotype, female, scale $1 \mathrm{~mm}$. - b. Holotype, head, dorsal view, scale $1 \mathrm{~mm}$. - c. Holotype, right ocelli and Tömösváry organ (c-To), scales $250 \mu \mathrm{m}$. - d. Paratype, maxilliped coxosternum, ventral view, scale $1 \mathrm{~mm}$. - e. Paratype, dental margin of maxilliped coxosternum, scales $250 \mu \mathrm{m}$. $-\mathrm{f}$. Holotype, female, posterior segments and gonopods, scale $500 \mu \mathrm{m}$. - g. Holotype, female, claw of gonopods, scale $250 \mu \mathrm{m}$. $-\mathrm{h}$. Paratype, male, posterior segments and gonopods, scale $500 \mu \mathrm{m}$.

weakly wrinkled, moderately smooth; T1 generally trapeziform, width equal to head shield, slightly narrower than $\mathrm{T} 3$, distinctly shorter than T1 and T3, T10 widest; posterior marginal ridge of T1, T3, T5 and T8 slightly concave, posterior angles generally rounded; posterior marginal ridge of T10, T12 and T14 with concave medial sector, posterior marginal ridge of T15 strongly concave, posterior angles of T14 and T15 with short triangular projections; medial sector of posterior margin of T2, T4, T6, T7, T9, T11 and T13 straight, posterior angles of $\mathrm{T} 2$ and $\mathrm{T} 4$ rounded, posterior angles of T6, T7, T9, T11 and T13 with sharply triangular projections (Fig. 2 a).

Short setae scattered sparsely over the surface of all tergites and along the lateral ridge of all ter- gites, more setae on anterior of each tergite; short setae scattered very sparsely on head shield.

All sternites generally trapeziform, setae scattered sparsely over surface and lateral borders of all sternites, more setae on anterior of each sternite. In male, setae obviously thicker on posterior of sternite 13, thickest on sternite 14, however, only few long setae on sternite 15 , short setae greatly reduced, a row of longer setae arranged in order along the posterior margin. In female, only short to moderately long setae on posterior and posterior lateral margin of sternite 14, very sparse on sternite 15 .

Legs strong; coxa, prefemur, femur, tibia of legs 1-13 with setae scattered sparsely on surface, fewer setae on both the dorsal and the ven- 
Table 2. Leg spinulation of Bothropolys edgecombei sp. n. Letters in brackets indicate individual variation in spinulation. Abbreviations as in Table 1.

\begin{tabular}{|c|c|c|c|c|c|c|c|c|c|c|}
\hline \multirow[b]{2}{*}{ Legs } & \multicolumn{5}{|c|}{ Ventral } & \multicolumn{5}{|c|}{ Dorsal } \\
\hline & C & $\mathrm{Tr}$ & $P$ & $\mathrm{~F}$ & $t$ & $C$ & $\mathrm{Tr}$ & $\mathrm{P}$ & $F$ & $t$ \\
\hline $1-8$ & & & $\mathrm{mp}$ & amp & $\mathrm{am}$ & & & amp & ap & ap \\
\hline 9 & & & (a)mp & amp & $\mathrm{am}$ & & & $a m p$ & ap & ap \\
\hline 10 & & & $\mathrm{amp}$ & amp & am & $\mathrm{m}$ & & amp & ap & ap \\
\hline 11 & & & amp & $\mathrm{amp}$ & $\operatorname{am}(p)$ & $\mathrm{m}$ & & amp & ap & ap \\
\hline 12 & & $\mathrm{~m}$ & amp & amp & $\operatorname{am}(p)$ & $\mathrm{m}$ & & $a m p$ & $\mathrm{p}$ & $\mathrm{p}$ \\
\hline 13 & $a$ & $\mathrm{~m}$ & amp & amp & amp & $\mathrm{m}$ & & amp & $p$ & $p$ \\
\hline 14 & $a$ & $\mathrm{~m}$ & amp & am & a & $\mathrm{m}$ & & $a m p$ & $\mathrm{p}$ & $p$ \\
\hline 15 & $\mathrm{am}$ & $\mathrm{m}$ & amp & $\mathrm{m}$ & a & $\mathrm{m}$ & & amp & $p$ & \\
\hline
\end{tabular}

tral side; a few slightly to indistinctly thickened setae encircling distal margin of coxa and prefemur; many moderately long setae arranged regularly on tarsus, one row of thicker, long setae regularly arranged on medial ventral side of basitarsus, two rows of thicker, long setae arranged on medial ventral side of distitarsus, a shallow channel between two rows of setae, up to $33 \%$ length of distitarsus; few setae on tarsus of legs 14 and 15, without setae arranged into rows.

Pretarsus claws on all legs, moderately long, curved ventrad; a moderately long accessory claw on both anterior and posterior of legs 1-13, anterior accessory claw very small, hardly visible, posterior accessory claw moderately large, no accessory claws on legs 14 and 15; basitarsus 6.3 (individual variation 6.3-6.5) times longer than wide, distitarsus $40 \%$ (individual variation $38 \%-41 \%$ ) length of tarsus on legs 15 . Leg spinulation in Table 2.

Coxal pores round or slightly ovate, small to moderately large, 28 (individual variation 9-28) coxal pores arranged irregularly, females 13-28, males 9-25, females usually more than males. Coxal pore field set in a moderately deep groove, separated from anteroventral face of coxa by an elliptical surface.

Female $15^{\text {th }}$ sternite straight posteromedially. Tergites of genital segment and telson usually well sclerotised. Sternite of genital segment large, posterior part sloping to backside, posterior margin moderately deeply concave between condyles of gonopods except for small median bulge, distal lightly sclerotised; setae evenly scattered on sternite of genital segment, regularly fringed with longer setae along the posterior margin. Gonopods divided into three articles, the first article bearing 2+2 moderately long, bullet-shaped spurs, inner spur slightly smaller than outer (Fig. $2 \mathrm{f}$ ). First and second article with many short to moderately long setae; setae of first article usually arranged in 5 irregular rows, gradually thicker from anterior to posterior; 7-9 (individual variation 12-18) moderately long setae of second article usually fairly scattered; 3 (individual variation 3-5) moderately long setae on outer lateral side of third article. Claw broad, tridentate (Fig. 2 $\mathrm{g}$ ), outer and inner denticles symmetrical, about equal in size.

Male $15^{\text {th }}$ sternite straight posteromedially, posterior part semicircular, scattered with 4-6 moderately long setae along the lateral margin; hardly any setae along the posterior margin; tergites of genital segment comparatively smaller than in female, usually well sclerotised. Posterior margin of the sternite of the genital segment quite deeply concave between gonopods, no bulge medially; comparatively long setae about evenly scattered on the ventral surface; gonopods short and small, only a small bulge, with 6-9 long setae on surface, terminal slightly sclerotised (Fig. 2 h).

Habitat. The specimens have been collected from broadleaved forest. They inhabit moderately moist habitats under roadside stones.

Etymology. The specific name is a patronym in honor of Dr. Greg Edgecombe, a myriapodologist of Australia, who contributed to this research.

Discussion. The new species is similar to $B$. rugosus Meinert, 1872 from Japan, China, Korea, 


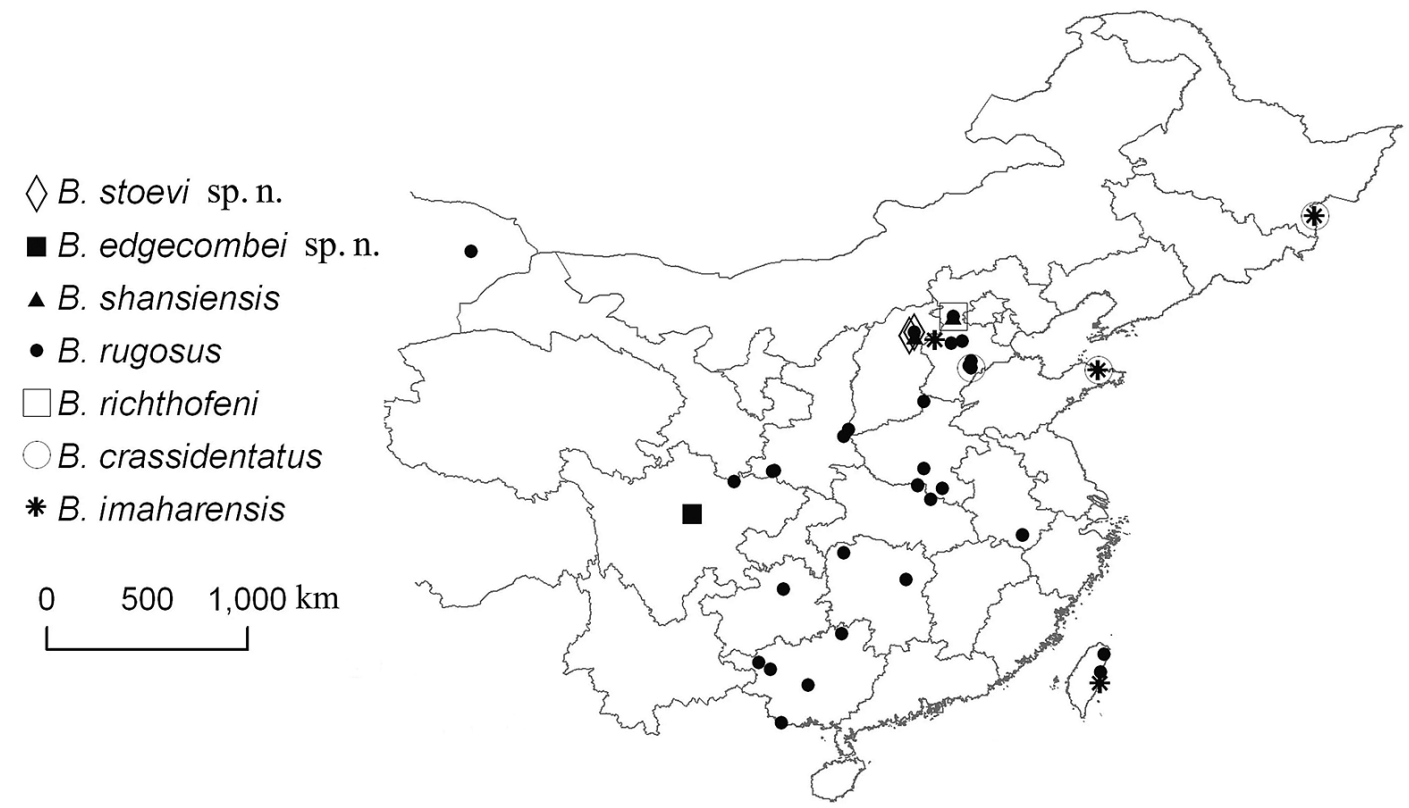

Fig. 3. Map of distributions of Chinese Bothropolys species.

the Philippines, and introduced to Hawaii (Zapparoli \& Shelley, 2000), in the same number of teeth on the dental margin of the maxilliped coxosternite; the first article of the female gonopod bearing $2+2$ spurs; but it is obviously distinguished from the latter by teeth on dental margin of maxilliped coxosternite truncated terminally instead of sharp; porodonts situated between outer two teeth rather than posteriolateral to the lateral tooth; posterior angles of T6, T7 with sharply triangular projections in B. edgecombei, vs. T6 and T7 in B. rugosus less sharply triangular projections.

\section{Key to Chinese Bothropolys species}

To assist in the identification of species described in this work and other recorded species of Chinese Bothropolys, the following key is offered. This key emphasizes characters that can be examined without much dissection or high-magnification microscopy; moreover, these characters are specific to taxa occurring in China. The distributions of Chinese Bothropolys species are shown in Fig. 3. 1a. Feebly triangular projections on tergites $7 \quad 2$

1b. Pronounced triangular projections on tergites 7

2a. No projections on tergites $6 \quad$ B. stoevi sp. n.

2b. Feebly triangular projections on tergites 63

3a. Maxillipede dental margin with 9-10 teeth, female gonopod with 3 spurs

B. imaharensis Verhoeff, 1937

3b. Maxillipede dental margin with 7-8 teeth 4

4a. Female gonopod with 3-5 spurs, about 20 ocelli on each side

B. rugosus (Meinert, 1872)

4 b. Female gonopod with one spur, about 25 ocelli on each side

B. crassidentatus

Takakuwa \& Takashima, 1949

5a. Maxillipede dental margin with 9-10 teeth, female gonopod with 2-3 spurs

B. richthofeni Verhoeff, 1938

5b. Maxillipede dental margin with 6-8 teeth, female gonopod with 2 spurs

6a. Pronounced projections on tergites 4, maxillipede teeth sharp B. shansiensis

Takakuwa \& Takashima, 1949

6b. No projections on tergites 4 , maxillipede teeth truncated

B. edgecombei isp.n. 
Acknowledgements. This study was supported by the Key Project of the National Natural Science Foundation of China (NSFC Key Project -30630010) and Project of the National Natural Science Foundation of Department of Education of Hebei Province (Z2008125). We are grateful to Dr. Gregory D. Edgecombe, London, U. K., and Dr. Pavel Stoev, Sofia, Bulgaria, for their hospitality and everlasting help during our research, and advice and comments on the manuscript, respectively. We thank Alessandro Minelli's suggestions improved the manuscript. We wish also to thank Dr. Marzio Zapparoli, Viterbo, Italy, Dr. Rowland M. Shelley, North Carolina, USA, and Dr. His-Te Shih, Taichung, China, for providing us with invaluable literature. Thanks must go to Dr. Zi-Zhong Yang and Dr. ZhiSheng Zhang for their help in preparing the paper.

\section{References}

Attems, C. 1938: Myriopoden von Hawaii. - Proceedings of the Zoological Society of London, B 108: 365-387.

Attems, C. 1953: Myriopoden von Indochina. Expedition von Dr. C. Dawydoff (1938-1939). — Mémoires du Muséum National d'Histoire Naturelle Paris. Série A, 5 (3): 133-230.

Chamberlin R. V. 1925: The Ethopolidae of America north of Mexico. - Bulletin of the Museum of Comparative Zoology 57 (7): 385-437.

Chamberlin R. V. \& Wang Y. H. M. 1952: Some records and descriptions of Chilopods from Japan and other oriental areas. - Proceeding of the Biological Society of Washington 65: 177-188.

Chao, J. L. 2005: Review and development of study on Chilopoda of Taiwan. - Journal of Endangered Wild Animal 9 (4): 33-41.
Eason, E. H. 1997: On some Lithobiomorpha from the mountains of Kirghizia and Kazakhstan (Chilopoda). - Arthropoda Selecta 6 (1-2): 117-121.

Matic, Z. 1974: Contribution to the knowledge of the genus Bothropolys (Lithobiomorpha: Ethopolidae). Annales Zoologici 31 (2): 329-341.

Takakuwa, Y. 1939: 9 Bothropolys-Arten aus Japan. Transactions of the Natural History Society of Formosa 29 (188): 103-110.

Takakuwa, Y. 1940: Class Chilopoda, Epimorpha, Lithobiomorpha. - Fauna Nipponica Vol. 9, Fas. 8, No. 3. 104 pp. Sanseido Book Store, Tokyo.

Takakuwa Y. \& Takashima H. 1949: Myriapods collected in Shansi, North China. — Acta Arachnologica 11 (12): 51-69.

Verhoeff, K. W. 1938a: Über einige ostasiatische Lithobiiden. - Zoologischer Anzeiger 123 (4): 99-105.

Verhoeff, K. W. 1938b: Chilopoden-Studien zur Kenntnis der Epimorphen. - Zoologische Jahrbücher, Abteilung für Systematik 71: 339-388.

Wang, D. Q. \& Mauriès J. P. 1996: Review and perspective of study on Myriapodology of China. - Acta Myriapodologica 169: 81-99.

Zalesskaja, N. T. 1978: Identification book of the lithobiomorph centipedes of the USSR (Chilopoda: Lithobiomorpha). Moscow. Nauka. 212 pp.

Zapparoli M. 2006: Lithobiidae. — In: Minelli A. (ed.) A World Catalogue of Centipedes (Chilopoda). [www document]. URL http://chilobase.bio.unipd.it/docs/ chilobase.php (Accessed 8 May 2007).

Zapparoli, M. \& Shelley, R. M. 2000: The centipede order Lithobiomorpha in the Hawaiian Islands (Chilopoda). I. The epigean fauna. Records of the Hawaii Biological Survey for 1999. - Bishop Museum Occasional Papers 63: 35-49. 